(RESEARCH ARTICLE)

\title{
Profile of intrauterine contraceptive device (IUCD) acceptors at the Rivers State University Teaching Hospital, Southern Nigeria
}

\author{
Nonye-Enyidah Esther ${ }^{1,}{ }^{*}$ and EjikemMazi EC 2 \\ ${ }^{1}$ Department of Obstetrics and Gynaecology, Rivers State University Teaching Hospital, Port Harcourt, Rivers state, \\ Nigeria. \\ ${ }^{2}$ Department of Obstetrics and Gynaecology, Abia State University Teaching Hospital, Aba, Abia state, Nigeria.
}

Publication history: Received on 30 November 2019; revised on 12 December 2019; accepted on 16 December 2019

Article DOI: https://doi.org/10.30574/wjarr.2019.4.2.0099

\begin{abstract}
Intrauterine Contraceptive Devices are among the safest and most effective reversible contraceptives used worldwide. It is also the most effective emergency contraception and particularly suitable for women in developing countries as they are affordable, convenient and do not require frequent visits to the clinic. To review the profile and prevalence of intra uterine contraceptive device acceptors at the Rivers State University Teaching Hospital (RSUTH). A 10 year retrospective review of all 814 clients' records that accepted intrauterine contraceptive device in the family planning clinic of the hospital from $1^{\text {st }}$ January 2008 - 31 ${ }^{\text {st }}$ December 2017. Data was extracted, coded and analyzed using the statistical package for social sciences (SPSS) IBM version 25.0 (Armonk, NY).There were 1893 contraceptive acceptors during the study period, out of which 814 (43\%) accepted the IUCD, which was the highest compared to other contraceptives. Majority of the clients 762 (93.6\%) were between the age range of 25-44 years, married 779 (96\%), multiparous 512 (62.9\%), Christians 779 (96\%) and 805 (98.9\%) had formal education with secondary level of education being the highest, 610 (74.9\%). Clinical personnel were the commonest source of information, accounting for 634 (77.9\%). Though the uptake rate of IUCD was the highest among the contraceptives in the family planning clinic during the study period, there is still need to improve on its uptake by creating more awareness including on its effectiveness as an emergency contraception.
\end{abstract}

Keywords: Contraception; Intrauterine contraceptive devices; Acceptors; RSUTH

\section{Introduction}

Unwanted pregnancy, high fertility rates and high parity have been associated with high maternal mortality rate in Nigeria [1,2]. Fortunately, contraception has shown to reduce unwanted pregnancy. Despite known benefits and strategic role of contraception in reducing maternal and infant mortalities, family planning acceptance and utilization is low in developing countries including Nigeria [3, 4].

IUCDs are among the safest and most effective forms of contraceptives developed by the population council and are used by about 128 million women worldwide [5]. It is the commonest method of contraception amongst women in developing countries $[6,7]$. They have a service life of 10-12 years and produce few side effects. The second generation IUCDs are improvements over the first generation inert ones delivering either copper or hormones implanted on them. The two main types of IUCDs are non-hormonal metallic (copper) and hormonal levonorgestrel releasing intrauterine system (LNG-IUS) like Mirena and Jaydess [4, 5]. The LNG-IUS reduces menstrual loss and is more popular in developed countries [7]. It is not used for emergency contraception unlike Copper T380A which is a very effective form of emergency contraception. The IUCDs stimulate marked inflammatory reaction in the uterus. The concentration of the macrophages, leucocytes, prostaglandins and various enzymes in both uterus and tubal fluid interfere with the

\footnotetext{
${ }^{*}$ Corresponding author

E-mail address: hernsi@yahoo.com
} 
transport of spermatozoa and ova. They also prevent implantation should a healthy fertilized ovum reach the endometrial cavity [9-11].

Generally pregnancy rates for current IUCD (including the TCu380A, which is the only IUCD available in our family planning clinic) are less than 1 per 100 woman years [12-14]. Since the introduction of IUCD in our hospital, there has been no recorded study evaluating its use. This study was carried out to determine the socio-demographic characteristics of IUCD acceptors in our centre, the uptake rate and the reason for taking this type of contraception. The findings in comparison with other findings from other centres will help to develop recommendations that will improve contraceptive services and uptake.

\section{Material and methods}

This retrospective study was carried out at the family planning clinic of the Rivers State University Teaching Hospital (RSUTH), a newly established teaching hospital in Port Harcourt, the capital of Rivers State in South-South geopolitical zone of Nigeria. The clinic gets its clients from within and outside the hospital. It has its own records section different from the hospital records and this makes it easy to retrieve the clients' case notes.

At presentation, the clients were warmly welcomed by trained family planning nurses and physicians who also counseled them. The clients were allowed to make informed choice based on their needs and available contraceptives suitable for them. Thereafter medical history and clinical examination were done. Urine analysis and pregnancy test were also done for the clients. Those that chose IUCD were those with normal menstrual periods and who did not have pelvic inflammatory disease at least in the past three months. All the IUCD were inserted in the first 7 days of menstruation after excluding pregnancy and they were Copper T380A variety.

The record cards of all the clients that accepted IUCD between $1^{\text {st }}$ January, 2008 and $31^{\text {st }}$ December, 2017 were retrieved and studied. The information extracted from the cards included the socio-demographic characteristics of the clients, indications for their use and source of information concerning contraception. The data was analyzed with the statistical package for social sciences (SPSS) IBM version 25.0 (Armonk, NY) using frequency counts and percentages.

\section{Results}

During the study period, there were 1893 contraceptive acceptors out of which 814 women (43\%) accepted IUCD. All the IUCDs inserted were copper T380A (CuT 380A) variety, inserted in the first 7 days of menstruation after excluding pregnancy. Six hundred and twenty four (76.7\%) women used IUCD for birth spacing, 180 (22.1\%) have completed their family size and used it to prevent further pregnancy. There was no reason for the use of IUCD indicated in the cards of $10(1.2 \%)$ clients.

The ages of the clients ranged from 15 to 50 years. Majority of the clients 459 (56.4\%) were between the age range of 25 to 34 years. The mean age was $33.66 \pm 5.53$ years. Majority of the clients were multiparous women, $512(62.9 \%)$ and Christians $779(95.7 \%)$. The parity range was 0 to 12 and modal parity was para 3. Five (0.6\%) were nullipara while 219 (26.9\%) were grandmultipara. Eight hundred and five (98.9\%) of the clients had formal education out of which 610 $(74.9 \%)$ had secondary level of education while $157(19.3 \%)$ and $38(4.7 \%)$ had tertiary and primary levels of education respectively.

Majority of the clients were married 779(95.7\%) while 35 (4.3\%) were single. The occupation of the clients were not documented in the patients' cards therefore could not be analysed. The socio-demographic characteristics of the OCP acceptors are shown in table 1.

Sources of information on contraception are shown in table 2. Six hundred and thirty four (77.9\%) women obtained their information concerning contraception from clinical personnel, 79 (9.7\%) from friends and relatives, 33 (4.0\%) from community health workers and 20 (2.5\%) from print and media. Radio/Television and outreach contributed 15 $(1.8 \%)$ and $12(1.5 \%)$ respectively.

Table 3 shows the yearly trend of acceptors of IUCD. In 2008, 115 (48.5\%) women accepted and used IUCD; 2009 recorded the highest use, 148 (67.3\%) and 2013 second to that, accounting for 104 (61.2\%) women. In 2010, 2011and $2012,111(42 \%), 85$ (49.4\%) and 33 (16.6\%) women used this type of contraception respectively. After 2013, there was a decline in the use of IUCD up to 2017 that recorded 59 (42.1\%) women. 
Table 1 Socio-demographic characteristics of the clients

\begin{tabular}{lll}
\hline Variable & No. & $\begin{array}{l}\text { Percentage } \\
\text { AGE) }\end{array}$ \\
\hline$<20$ & 1 & 0.1 \\
$20-24$ & 22 & 2.7 \\
$25-29$ & 165 & 20.3 \\
$30-34$ & 294 & 36.1 \\
$35-39$ & 197 & 24.2 \\
$40-44$ & 106 & 13.0 \\
$45-49$ & 26 & 3.2 \\
$\geq 50$ & 3 & 0.4 \\
\hline EDUCATIONAL STATUS & & \\
\hline No formal education & 9 & 1.1 \\
Primary & 38 & 4.7 \\
Secondary & 610 & 74.9 \\
Tertiary & 157 & 19.3 \\
\hline RELIGION & & \\
\hline Christianity & 779 & 95.7 \\
Islam & 14 & 1.7 \\
Others & 21 & 2.6 \\
\hline PARITY & & \\
\hline Nullipara & 5 & 0.6 \\
Primipara & 78 & 9.6 \\
Multipara & 512 & 62.9 \\
Grand multipara & 219 & 26.9 \\
\hline MARITAL STATUS & & \\
\hline Single & 35 & 4.3 \\
married & & 95.7 \\
\hline & & \\
\hline & & \\
\hline & & \\
\hline & & \\
\hline & & \\
\hline
\end{tabular}

Table 2 Sources of information on contraception

\begin{tabular}{lll}
\hline Sources of Information & No. of clients & Percentage (\%) \\
\hline Clinical personnel & 634 & 77.9 \\
Friends/relatives & 79 & 9.7 \\
Community Health Worker & 33 & 4.0 \\
Print Media & 20 & 2.5 \\
Radio/Television & 15 & 1.8 \\
Outreach & 12 & 1.5 \\
Others & 21 & 2.6 \\
\hline
\end{tabular}


Table 3 Yearly trend of acceptors of Oral contraceptive pills.

\begin{tabular}{llcl}
\hline Year & No & Total no. of contraceptive users & Percentage (\%) \\
\hline 2008 & 115 & 237 & 48.5 \\
2009 & 148 & 220 & 67.3 \\
2010 & 111 & 264 & 42.0 \\
2011 & 85 & 172 & 49.4 \\
2012 & 33 & 199 & 16.6 \\
2013 & 104 & 170 & 61.2 \\
2014 & 57 & 138 & 41.3 \\
2015 & 46 & 175 & 26.3 \\
2016 & 56 & 178 & 31.5 \\
2017 & 59 & 140 & 42.1 \\
\hline
\end{tabular}

\section{Discussion}

The study showed that out of 1893 contraceptive acceptors during the study period, 814 (43\%) accepted IUCD making it the most commonly accepted method of contraception in our centre. This is similar to the studies done in other centres in the country [15-17]. The acceptance rate is similar to $42 \%$ recorded in another study done in Port Harcourt [18]. In our centre CuT380A was the only IUCD available and was then inserted. It has low pregnancy rate, long term effectiveness and lower risk of expulsion. Therefore it is now the first choice IUCD globally and also the gold standard $[16,19,20]$.

The acceptance of IUCD was high between 25 and 29 years, higher between 35 and 39 years and highest between 30 and 34 years. This is similar to other studies done in Enugu and Abakaliki $[3,21]$. The teenager who accepted and used the IUCD during the study period was married. The age range 25-39 years represent the peak period of reproductive life as more women are postponing pregnancy and child bearing in Nigeria because of girl child education which is now popular in Nigeria [22]. There was no provision for the occupation of the clients in the cards. This has to be included in subsequent cards.

Majority of the acceptors (95.7\%) were married since this method of contraception is particularly for those women who are in stable relationship as in marriage [23]. This finding is in keeping with the users of IUCD in other studies [15, 17, 23]. This also shows that our government family planning clinics are primarily directed towards mature females in stable relationship [23]. The low uptake among the teenagers could be due to the cultural and religious restrictions on premarital sex and general misconception that associates adolescent contraception with sexual permissiveness [15]. Several studies have shown higher risk of expulsion of IUCD and pelvic inflammatory disease (PID) among teenagers and nulliparous women who possibly have multiple sexual partners [24, 25]. Hence IUCDs may not be the first choice contraceptives in teenagers.

In this study, multiparous women had the highest acceptance rate of $62.9 \%$. This is in keeping with similar studies done in Calabar and Port-Harcourt $[7,15,23]$. Our study showed that $26.9 \%$ of grandmultiparous women accepted IUCD and $180(22.1 \%)$ women with complete family size (most of them grandmultipara) also accepted to use IUCD instead of sterilization. In our environment, acceptance of sterilization due to cultural reasons is very low $[1,16]$ therefore CuT380A whose pregnancy rates have been shown to be consistently less than $1 \%$ and whose effectiveness rivals that of surgical sterilization [16] would be an excellent contraceptive option for these group of women.

Majority of acceptors in this study are educated with the highest having secondary education. This is in keeping with the observation by experts that educated African couples are more likely to accept modern methods of contraception than the uneducated ones [23]. Most of the clients are Christians. This is not surprising as majority of the population in south south part of Nigeria are Christians.

More than 600 women (77.9\%) derived their source of information on IUCD from clinical personnel. This is similar to studies done in other centres $[6,7,23]$ but in contrast to the study done in south western Nigeria where print and media played a very important role in the dissemination of information concerning contraception [26]. Unfortunately, commonly held rumors, misconceptions and lack of current scientific information have been identified as the biggest barrier to IUCD acceptance and use. These are currently contributing to the decline in the acceptance and use of IUCD 
in Nigeria and other African countries [26]. Other reasons adduced for the low contraceptive acceptance in Nigeria and other developing countries include ignorance, illiteracy, poverty, inadequate funding and poor organization of health care system [26]. Print and media contributed to $2.5 \%$ of sources of information on IUCD in our study. Hence to have an increase in the uptake rate of contraceptives, the source of information should go beyond the clinical personnel to the communities through NGOs and mass media as many women may not have the cause to go to the hospital for treatment. Therefore there should be intense accurate information dissemination to increase the uptake of IUCD especially now that the uptake rate is reducing.

In this study, all the IUCD insertions were done within seven days of onset of menstruation after ruling out pregnancy. This time of insertion is associated with less discomfort and is generally easier to perform as the cervical canal is dilated. In addition, insertion related bleeding is masked during this time of insertion. IUCDs can also be inserted immediately post-partum but not more than 48 hours after delivery and post abortion [12, 27]. In our study, there were no post abortal or post-partum insertions. Levonorgestrel releasing intrauterine system (LNG-IUS) is yet to be made available in the family planning clinic of the hospital. IUCD has been cited by some workers as the best emergency contraception. Though the awareness of its use as an emergency contraception in our centre is very low, none of the clients used the IUCD for emergency contraception.

\section{Conclusion}

The study showed that acceptors of IUCD were young, married. Multiparous and educated women whose sources of information on contraceptive use were mainly from clinical personnel. Efforts should be made on mass media involvement in the dissemination of accurate information about IUCD, including its use as an emergency contraception. This will go a long way in increasing the uptake in our environment.

\section{Compliance with ethical standards}

\section{Acknowledgments}

We wish to express our profound gratitude to the staff of the family planning clinic for the assistance rendered for this study.

\section{Disclosure of conflict of interest}

Authors have declared that no competing interests exist.

\section{Statement of ethical approval}

Ethical approval was given by the hospital's ethics committee.

\section{References}

[1] Igwegbe AO, Ugboaja JO andMonago EN. (2010). A ten year clinical experience with intrauterine contraceptive device (IUCD) in a Nigerian tertiary health institution. International Journal of Medicine and Medical Sciences, 2(11), 347-353.

[2] Galadanci HS. (2009). Maternal mortality. In: Ikpeze OC (Ed), Fundamentals of Obstetrics and Gynaecology. Africana First Publishers, 159-166.

[3] Igwe NM. (2016). Intrauterine Contraceptive Device Use in Abakaliki, south east Nigeria. A 5 year review. Tropical Journal of Medical Research, 19, 138-143.

[4] Emuveyan EE. (2005). Advances in contraception. In: Kwawukume EY, Emuveyan EE (Eds.). Comprehensive Gynaecology in the Tropics. Graphic packaging Ltd, Accra, 233-241.

[5] Speroff I andDarney P. (2010). Intrauterine contraception. In: Lippicot Williams and Wilkins (Eds). A Clinical Guide for Contraception. Philadelphia Pa, USA, 239-280.

[6] Ojule JD andMacPepple DA. (2011). Family planning practice in a tertiary health institution in Southern Nigeria. West African Journal of Medicine, 30, 178-181.

[7] Dimkpa OJ, Okwudili OE andWamadi NE. (2014). Intrauterine contraceptive use in Port Harcourt, southern Nigeria. A retrospective analysis. British Journal of Medicine and Medical Research, 4, 3132-9. 
[8] Shimoni N. (2010). Intrauterine contraceptives: a review of users, side effects and candidiasis. Reproductive Medicine, 28(2), 118-125.

[9] Hardeman J and Weiss BD. (2014). Intrauterine Devices: An Update. American Family Physician, 89(6), 445-450.

[10] American College of Obstetricians and Gynaecologists. (2011). ACOG Practice Bulletin No. 121. Long acting reversible contraception: Implants and Intrauterine Devices. Obstet. Gynaecol. 118(1), 184-196.

[11] Winner B, Peipert JF, Zhao Q et al. (2012). Effectiveness of long acting reversible contraception. New England Journal of Medicine, 366(21), 1998-2007.

[12] Shukla M, Qureshi S andChandrawati S. (2012). Post placental intrauterine device insertion. A 5 year experience at a tertiary care centre in North India. Indian Journal of Medical Research, 136(3), 432-435.

[13] Trussell J. (2011). Contraceptive failure in the United States. Contraception, 83(5), 397-404.

[14] Trussell J. (2012). Update on and correction to the cost effectiveness of contraceptives in the United States. Contraception, 85(2), 218.

[15] Abasiattai AM, Bassey EA andUdoma EJ. (2008). Profile of Intrauterine contraceptive device acceptors at the University of Uyo Teaching Hospital, Uyo Nigeria. Annals of African Medicine, 7(1), 1-5.

[16] Dinwoke VO, Okafor CI and Eke A. (2015). Intrauterine contraceptive device acceptors in NnamdiAzikiwe University Teaching Hospital, Nnewi, south eastern Nigeria - A 5 year review. Tropical Journal of Medical research, 18(2), 68-73.

[17] Akinola IO, Fabanwo AO, Gbadegesin A, Tayo AO and Adebayo SK. (2006). A survey of family planning clinic attendance in an urban central public health facility. Tropical Journal of Obstetrics and Gynaecology, (suppl 1): S34.

[18] Ojule JD, Oriji VK andOkongwu C. (2010). A 5 year review of the complications of progestogen only injectable contraceptives at the UPTH. Nigerian Journal of Medicine, 19(1), 87-95.

[19] Almond TE. Contraceptive efficacy of IUDs. (2008). American Journal of Obstetrics and Gynaecology, 198, 193198.

[20] Catherine d'Arcanques. (2007). Worldwide use of intrauterine device for contraception. Contraception, 75, S2S7.

[21] Ezegwui HU, Ikeako LC andEgbuji C. (2011). Missing IUCD amongst clients in Enugu, Nigeria. Nigerian Journal of Surgery, 17, 60-63.

[22] Chigbu B, Onwere S, Aluka C et al. (2010). Contraceptive choices of women in rural south eastern Nigeria. Nigerian Journal of Clinical Practice, 13(2), 195-199.

[23] Enyidah CE, Ojule DE and Bassey G. (2011). Contraception with intrauterine contraceptive device (IUCD) in Port Harcourt, south south Nigeria. Journal of Biomedical Sciences, 11(1), 35-45.

[24] Hubacher D, Grimes DA andGemzell-Danielsson K. (2013). Pitfalls of research linking the intrauterine device to pelvic inflammatory disease. Obstst. Gynaecol, 121, 1091-8.

[25] Hubacher D. (2014). Intrauterine devices and infection: Review of the literature. Indian Journal of Medical Research, 140(suppl 1), S53-S57.

[26] Adekunle AO. (2003). Recent advances in contraceptive development. In: Okonofua FE, Odunsi K (Eds). Contemporary Obstetrics and Gynaecology for developing countries. Women's Health and Action Research Centre, 514-529.

[27] Sood B, Asif R, Charurat E et al. (2012). Revitalization of Postpartum IUCD (PPIUCD) services: experience from India. Contraception, 86(2), 184-185.

\section{How to cite this article}

Nonye-EE and Ejikem ME. (2019). Profile of intrauterine contraceptive device (IUCD) acceptors at the Rivers State University Teaching Hospital, southern Nigeria.World Journal of Advanced Research and Reviews, 4(2), 96-101. 